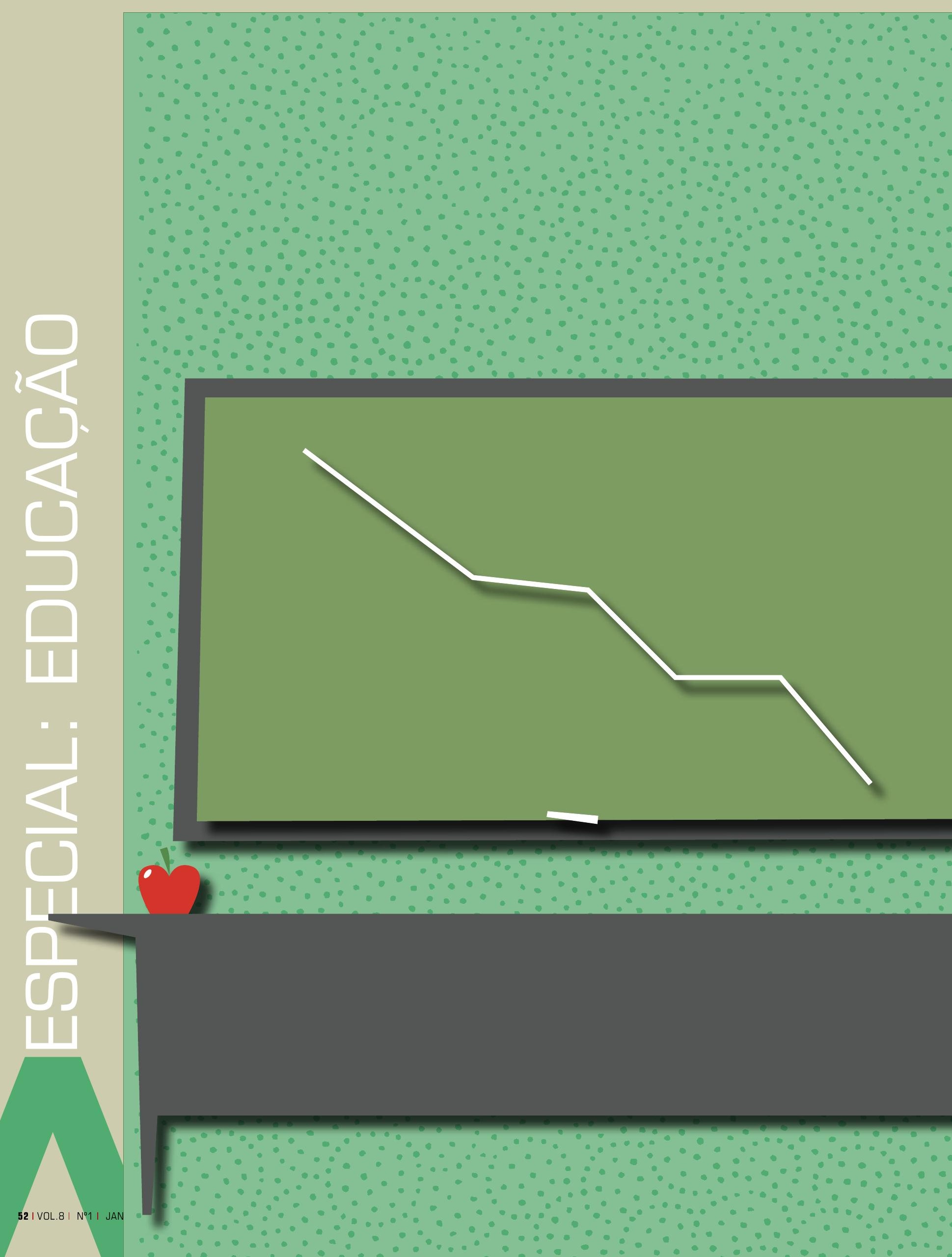




\section{PANORAMA DO ENSINO}

\section{0 setor de ensino superior privado passa por um momento de consolida-}

ção no Brasil, marcada pela entrada de capital estrangeiro e por uma forte pressão para o incremento da qualidade

POR EDSON PINTO DE ALMEIDA

0 ensino superior no Brasil se transformou em um grande negócio. Não há duplo sentido nessa afirmação - é a pura realidade. Desde 1998, quando a legislação passou a permitir que instituições com fins lucrativos pudessem atuar no setor, foram abertas mais de 1.300 escolas no país. Essa expansão ganhou uma nova dimensão nos últimos três anos, o que pode ser uma boa notícia. Para os especialistas do setor, com mais recursos e uma gestão profissionalizada, o nível do ensino tende a melhorar em virtude da maior competição.

O cenário atual mostra que estão saindo de cena as pequenas instituições, de origem familiar, para dar lugar aos grandes grupos educacionais, altamente profissionalizados e capitalizados por dinheiro captado na Bolsa de Valores ou por injeção de recursos de parceiros internacionais e fundos de investimento. O mercado de capitais, no período de um ano, recheou em cerca de R\$ 2 bilhões os cofres das redes Anhanguera, Estácio de Sá, SEB e Kroton, que juntas reúnem um contingente de 358.667 alunos em todo o Brasil.

O objetivo desses grupos é ganhar escala para poder competir com margens acima de $20 \%$. O ritmo de fusões e aquisições é crescente. $\mathrm{O}$ volume movimentado em 2008 deve estar próximo dos $\mathrm{R} \$ 300$ milhões, pois nem todos os números são divulgados. Segundo levantamento da consultoria KPMG, ocorreram 30 transações no setor de educação no primeiro semestre de 2008, contra 17 no mesmo período de 2007. É o terceiro maior volume de fusões e aquisições nos primeiros seis meses de 2008. Os setores de tecnologia da informação e de alimentos, bebidas e fumo estão na frente se computadas as chamadas operações cross border, ou seja, envolvendo recursos estrangeiros. A comparação das transações domésticas dá a dianteira para o setor de educação.

Há grandes chances de esse ritmo diminuir por causa dos efeitos da crise americana na liquidez geral. Mas ainda é cedo para conclusões definitivas. Luiz Motta, diretor da KPMG, acredita que haverá uma redução do ímpeto dos grupos que estão indo às compras. A razão é simples. Os preços podem cair, e neste momento não dá para enxergar o fundo do poço. "Ninguém quer fazer um mau negócio", diz. O especialista Ryon Braga, da Hoper Consultoria, acredita que pode haver uma queda de $30 \%$ no valor dos múltiplos - o indicador que estabelece o valor final do negócio. O último estudo do JP Morgan mostrava que a média do mercado estava em $\mathrm{R} \$ 5.500$ por aluno. 
PROTEGIDOS DA CRISE. Para quem tem dinheiro em caixa, o cenário parece não prometer grandes alterações. É o caso da Anhanguera Educacional, um dos grupos mais agressivos em aquisições e que projeta um crescimento de $100 \%$ ao ano. Segundo o presidente da instituição, o professor de matemática Antonio Carbonari Netto, o grupo ainda tem no cofre metade dos $\mathrm{R} \$ 500$ milhões que amealhou na última oferta pública de ações, realizada em abril de 2008. Até 2012, a meta da Anhanguera é dobrar de tamanho e chegar a 120 campi, num total de 400 mil alunos - hoje tem cerca de 140 mil anos.

A última aquisição feita pela Anhanguera ocorreu na primeira quinzena de outubro. O grupo comprou por $\mathrm{R} \$ 180$ milhões a rede de ensino LFG, voltada para cursos preparatórios de pós-graduação à distância, com 70 mil alunos. A aquisição reforça a área de Ensino à Distância da Anhanguera. A LFG é forte em cursos preparatórios para o exame da OAB e concursos públicos. Possui 322 polos de ensino à distância em 290 cidades do país.

Entre os especialistas, especula-se que a voracidade da Anhanguera tem um motivo: a possibilidade de associar-se a um grupo estrangeiro. Como o mercado cresce rapidamente e os grupos maiores ocupam cada vez mais espaço no mercado, os grupos entrantes terão mais dificuldades ou pagarão muito caro para entrar. O grupo americano Apollo, associado ao fundo Carlyle, já fez uma oferta preliminar de $\mathrm{R} \$ 2,5$ bilhões pela Universidade Paulista (Unip), do Grupo Objetivo, a maior rede privada do país, com 198 mil alunos - mas o negócio não saiu.

A hipótese de associar-se, não confirmada pela Anhanguera, pode estar relacionada, na opinião de analistas, ao projeto que tramita na
Câmara, de autoria do deputado Ivan Valente, do PSOL, cujo objetivo é impedir a participação de capital estrangeiro no setor da educação. O limite estabelecido pela reforma universitária proposta pelo governo é de 30\%. A pressa da Anhanguera em crescer, ainda de acordo com especialistas nesse mercado, seria uma forma de antecipar-se a qualquer mudança para que não seja inviabilizada a negociação com algum investidor de fora.

CAPITAL ESTRANGEIRO. Para o consultor Ryon Braga, a entrada do capital estrangeiro não é prejudicial. "Haverá no mercado brasileiro no máximo três instituições com capital externo. A última coisa com que eles se preocupam é com a ideologia. Sou mais favorável a um grupo estrangeiro que invista em qualidade do que a um grupo nacional que só pense em crescimento, sem se preocupar com mais nada", diz.

Por enquanto há duas redes estrangeiras estabelecidas no país, ambas de origem americana. A de menor participação é o grupo Whitney, que em 2006 adquiriu por $\mathrm{R} \$ 23,5$ milhões 50\% de participação no capital das Faculdades Jorge Amado, de Salvador. O maior investimento no Brasil foi feito pela rede Laureate International Universities, que atua em 18 países, com um plantel de 300 mil alunos. Desde que se instalou no país, em 2005, o grupo não diminuiu o apetite para investir. Sua principal aquisição foi a Universidade Anhembi Morumbi, da qual já possui $71 \%$ de participação e pretende chegar a 80\% do controle até 2009.

A Laureate também controla a Universidade Potiguar (RN) e a Business School São Paulo (BSP). Em 2008, fez mais três aquisições: o Centro Universitário do Norte (Uninorte), no Amazonas, a 
Escola Superior de Administração, Direito e Economia (Esade), no Rio Grande do Sul, e a Faculdade Boa Viagem, do grupo BV, em Recife esta última em fase de conclusão. É o quarto maior grupo privado, com 70 mil alunos. Numa entrevista que concedeu ao jornal Valor Econômico, a diretora do grupo, Elizabeth Guedes, informou que ele já investiu R\$ 1 bilhão em aquisições.

CONSOLIDAÇÃO À VISTA. Espera-se, para os próximos anos, um rearranjo desse mercado. A expansão dos chamados grupos consolidadores (18 instituições), hoje se dá em todas as regiões do país, do Centro-Oeste ao Nordeste, no Sul, Sudeste e, com menos força, na região Norte. Para os especialistas, ao final desse processo restarão cerca de dez grandes grupos. O desenho final do mercado será semelhante ao de uma pirâmide.

No topo, estarão as escolas de nicho, destinadas às classes $\mathrm{A}$ e $\mathrm{B}$, como FGV, Ibmec e ESPM. A seguir virão as escolas premium, de grande escala e variedade de cursos, como FAAP, Mackenzie, PUC, Facamp. Abaixo estarão universidades e centros universitários de porte, como Anhembi Morumbi, Unip, seguidos pelas instituições multicampi, com boa localização e mensalidades na faixa de 300 a 400 reais, como é o caso da Anhanguera e Estácio de Sá.

A iniciativa privada é a principal responsável pela ampliação do acesso ao ensino superior no Brasil. O setor público atende a 27\% dessa demanda, enquanto as instituições privadas de ensino superior complementam os outros 73\%. A corrida ao ensino superior, segundo estudo feito pelo HSBC Global Research, é comandada por jovens trabalhadores das classes C e D, em busca de melhores oportunidades de trabalho. Para boa parte desse contingente, a oportunidade de ascensão surgiu com os programas de fomento ao ensino superior (ProUni e Fies) adotados pelo governo federal.

QUALIDADE QUESTIONADA. A criação de grande grupos educacionais na área do ensino superior levanta a discussão sobre a qualidade dos cursos ofertados. Para os especialistas dessa área, é preciso olhar essa expansão das universidades particulares em dois momentos: o primeiro, em 1998, quando a porteira se abriu e houve uma espécie de boom no mercado para atender a demanda que estava reprimida há anos. O segundo momento, vivido nestes últimos dois anos, mostra uma nova lógica do mercado: a quantidade é importante para ganhar escala, mas, com a competição acirrada, os principais diferenciais inclusive para atrair investidores - passam a ser a boa governança e a qualidade do ensino.

Com a divulgação do índice classificatório do MEC, em setembro de 2008, essa lógica ganhou mais força. Segundo o consultor Ryon Braga, as instituições estavam empenhadas, primeiro, em ganhar musculatura e fatias de mercado para depois investir com mais força em qualidade. Com a publicação do ranking, essa estratégia, na sua opinião deverá se inverter. "Quem não oferecer melhores cursos agora corre o risco de captar menos alunos e se desvalorizar", diz.

A qualidade, a seu ver, será o principal fator de sustentabilidade das instituições. O que reforça essa visão é o crescimento do crédito estudantil. Esse mecanismo ajuda o acesso do aluno a um ensino de melhor qualidade e, ao mesmo tempo, ajuda as instituições a sobreviver. Acaba beneficiando as instituições de melhor qualidade. 


\section{Panorama do ensino}

RANKING DOS GRUPOS CONSOLIDADORES DO ENSINO SUPERIOR PRIVADO NO BRASIL

\begin{tabular}{c|l|c|c|c|}
$\begin{array}{c}\text { Posição } \\
\text { no } \\
\text { Ranking }\end{array}$ & \multicolumn{1}{|c|}{ Nome da IES ou do Grupo } & $\begin{array}{c}\text { Estimativa Atual de } \\
\text { Alunos na Graduação } \\
\text { Presencial }\end{array}$ & $\begin{array}{c}\text { Participação } \\
\text { no Mercado } \\
\text { (market share) }\end{array}$ & 2007 \\
\hline 0 & Total de Matriculas no Setor Privado - Brasil & 3.858 .792 & $100.0 \%$ & 3.710 .378 \\
\hline 1 & Grupo do “Di Gênio” (UNIP + holding). & 198.309 & $5.1 \%$ & 192.830 \\
\hline 2 & Estácio Participações & 198.200 & $5.1 \%$ & 188.240 \\
\hline 3 & Anhanguera Educacional & 114.720 & $3.0 \%$ & 56.741 \\
\hline 4 & Laureate International & 69.201 & $1.8 \%$ & 43.500 \\
\hline 5 & Grupo UNIBAN (Universidade Bandeirantes) & 65.420 & $1.7 \%$ & 62.570 \\
\hline 6 & Grupo UNINOVE (Universidade Nove de Julho) & 59.112 & $1.5 \%$ & 59.420 \\
\hline 7 & Grupo UNIPAC (Universidade Presidente Antonio Carlos) & 58.920 & $1.5 \%$ & 57.829 \\
\hline 8 & Grupo UNIVERSO (Universidade Salgado de Oliveira) & 51.765 & $1.3 \%$ & 49.215 \\
\hline 9 & IUNI EDUCACIONAL & 47.762 & $1.2 \%$ & 38.652 \\
\hline 11 & Króton (Pitágoras + INED) & 36.230 & $0.9 \%$ & 17.977 \\
\hline 10 & Grupo UNICSUL (Universidade Cruzeiro do Sul) & 32.763 & $0.8 \%$ & 21.347 \\
\hline 13 & Grupo Universitário Maurício de Nassau & 23.740 & $0.6 \%$ & 15.640 \\
\hline 12 & Grupo Ânima (UNA + Unimonte) & 23.120 & $0.6 \%$ & 21.843 \\
\hline 14 & Grupo Splice (Newton Paiva + Facens) & 13.800 & $0.4 \%$ & 1.300 \\
\hline 15 & UB Participações (Unibrasil + seis faculdades no PR) & 18.512 & $0.5 \%$ & 11.439 \\
\hline 16 & Veris Educacional (IBMEC e IBTA) & 10.700 & $0.3 \%$ & 6.700 \\
\hline 17 & SEB (COC) & 9.517 & $0.2 \%$ & 3.495 \\
\hline 18 & Fanor (Banco Pactual) & 9.270 & 8.328 \\
\hline & & 1.041 .061 & 857.066 \\
\hline
\end{tabular}

Grandes bancos, como o Santander e Unibanco, estão entrando nesse segmento. A Ideal Invest, empresa especializada nessa área, fez um pesquisa com 100 mil alunos e constatou que eles preferem fazer cursos de melhor qualidade, com mensalidades acima de $\mathrm{R} \$ 700$. Para Braga, o mercado tem condições de oferecer cursos para públicos de diferentes níveis de renda. "Quando estão atendidas as demandas de localização e preço, o único diferencial que passa a valer é a qualidade", afirma.

Para Braga, embora o ranking do MEC influencie positivamente o setor, os critérios adotados são discutíveis, pois comparam coisas dife- 
rentes. "Há diversos matizes para avaliar a qualidade. Não se pode comparar públicos diferentes", diz. Os critérios dos MEC, segundo o consultor, tomam como base o Enade, a titulação dos professores, infra-estrutura e tempo de dedicação dos professores. "Esses critérios têm um impacto relativo na aprendizagem do aluno. Há pesquisas que mostram o seguinte: para os alunos de melhor nível de instrução, o aprendizado é maior na medida em que os professores tenham maior titulação. Quando os alunos têm um nível baixo, ocorre o contrário: quanto maior a titulação do professor, menor é o aprendizado. As instituições destinadas à baixa renda precisam de professores que falam a mesma língua do aluno", diz.

MODELOS DE ENSINO. Em recente entrevista concedida ao jornal O Estado de S. Paulo, a antropóloga e coordenadora científica do Núcleo de Pesquisa de Políticas Públicas da USP, Eunice Durham, condenou o que ela chama de ilusão brasileira do modelo único de ensino. Para ela, nem todos querem ir para a universidade com o objetivo de serem pesquisadores ou professores. Grande parte dos jovens, na sua opinião, busca um diploma para ganhar mais dinheiro. A antropóloga defende o modelo americano, de colleges, ou seja, um ensino de terceiro grau para formar mão-de-obra especializada, mas não necessariamente ligado a universidades.

De certa forma, os grandes grupos privados de ensino superior cumprem esse papel quando focam o jovem trabalhador que estuda à noite. O curso mais procurado é o de Administração, segundo levantamento da Hoper Educacional. É um sinal evidente de que os alunos buscam uma qualificação que lhes permita ascender profissionalmente. Quem trabalha em banco pode ser promovido a gerente como diplomana mão. Na Anhanguera Educacional, $85 \%$ dos alunos se enquadram nesse perfil.

FOCO NA BAIXA RENDA. O objetivo principal da maior parte dos grandes grupos é o público da classe $C$, que não pode pagar uma mensalidade alta mas precisa ter uma perspectiva de empregabilidade. E a realidade brasileira mostra que o potencial desse mercado é grande. No Brasil, o índice percentual de jovens entre 18 e 24 anos que estão matriculados em faculdades ou universidades está próximo de 20\%, enquanto no Chile alcança quase $45 \%$ e na Argentina, $61 \%$.

Uma pesquisa realizada em 2008 pelo Sindicato das Entidades Mantenedoras de Estabelecimentos de Ensino Superior no Estado de São Paulo (Semesp) revela que 72\% dos entrevistados tiveram aumento de salário e 69\% mudaram de cargo ou de empresa depois que terminaram o curso superior, ou no ano seguinte.

A pesquisa mostrou também que o mercado de trabalho absorve um maior contingente de alunos do ensino superior particular: $90 \%$ dos funcionários recém-formados e 93\% dos funcionários com até 25 anos, das grandes organizações do estado de São Paulo, são egressos de instituições particulares. O levantamento aponta que o ensino superior particular é o responsável pela formação universitária de $86 \%$ dos entrevistados, inclusive de jovens profissionais e funcionários de alto e médio escalão das grandes organizações do estado de São Paulo. 